\title{
Synthesis and research of photocurable protective coatings on the basis of olygoesteracrylates
}

\author{
O. A. Karsakova*, M. V. Kuzmin \\ Chuvash State University named after IN Ulyanov, \\ 15 Moskovsky pr., Cheboksary, 428015, Russia \\ *email: karsakova.lesya@yandex.ru
}

\begin{abstract}
In this work, photocurable protective coatings based on methacrylic acid esters have been developed and their physical and mechanical properties have been investigated. The photocurable compositions were obtained by mixing at different ratios the following methacrylic acid esters: polyethylene glycol dimethacrylate 400 and triethylene glycol dimethacrylate ether, polyethylene glycol dimethacrylate 400 and oligourethane dimethacrylate, polyethylene glycol dimethacrylate 400 and pentaerythritol tetraacrylate. For the obtained compositions, the viscosity was studied using a Brookfield rotary viscometer. To initiate polymerization, a mixture of initiators was used: benzoyl peroxide and benzoin. Curing of the obtained compositions was carried out under the influence of UV rays for 2-5 minutes. For photo-cured compositions, their physical and mechanical properties have been studied. It was found that the composition based on polyethylene glycol dimethacrylate modified with triethylene glycol dimethacrylate at a ratio of $70: 30$ has the highest strength.
\end{abstract}

Keywords: photocuring; protective coatings; polyethylene glycol dimethacrylate 400; triethylene glycol dimethacrylate ether; pentaerythritol tetraacrylate; oligourethane dimethacrylate; benzoyl peroxide; benzoin

Received: 30.10.2020. Accepted: 09.12.2020. Published:30.12.2020.

(c) Karsakova 0. A., Kuzmin M. V., 2020

\section{Introduction}

Currently, photoinitiated polymerization is really relevant; this is due to the fact that the field of application of photo-cured materials is increasing. This method of curing is used in the manufacture of lacquers, paints, adhesives, coatings, in stereolithography, 3D printing, dentistry, laser image printing, and microelectronics [1].

An important component of photopolymerizing compositions (photopolymers) are oligomers, which determine the main characteristics of the photo-cured material - chemical resistance, abrasion re- sistance, hardness, elasticity, tensile and flexural strength. Under the influence of UV rays, three-dimensional insoluble polymer systems are formed from the contained functional groups of the oligomer. For radical photopolymerization initiated by ultraviolet radiation, unsaturated polyethyracrylates are used: epoxyacrylates, complex polyester acrylates, simple polyester acrylates, aminomodified polyester acrylates, urethanacrylates [2].

Another component is monomers and diluents. They are used to regulate the viscosity of the system. The meaning 
of the mechanism of action of monomers in the process of ultraviolet curing is embedded in the polymer structure. Acrylic acid esters are considered more popular: tripropylene glycol diacrylate, hexadiol diacrylate and dipropylene glycol diacrylate. Also widely used are glycidylmethacrylates, low-viscosity derivatives of glycidylmethacrylate or methyl methacrylate and polyatomic alcohols, polyphenols, polyether polyols, polycarboxylic acids, their esters or anhydrides. When the functionality of acrylic monomers increases, their reactivity increases, but the elasticity of the product decreases [3].

The third component of the photocured composition is the initiators (photoinitiators). In the composition you need to enter the matter, that the absorption

\section{Experimental}

Polymer binders were prepared on the basis of acrylic monomers by mixing at a certain ratio of polyethylene glycol-400 dimethacrylate and triethylene glycol dimethacrylate, polyethylene glycol 400 dimethacrylate and oligourethandimethacrylate, polyethylene glycol-400 dimethacrylate and pentaerythritol tetraacrylate. To initiate polymerization, benzoyl peroxide and benzoin were used. Benzoyl peroxide and benzoin were dissolved

\section{Results and discussion}

The initialization mechanism is shown in Fig. 1.

The results of studying the viscosity of the photocurable compositions according to the Brookfield viscometer and the compressive strength of the obtained photocurable protective coatings are given in Table 1 and Table 2.

From Table 1 it can be seen that the highest viscosity at room temperature radiation of a certain wavelength will go into an excited state, followed by molecular breakdown, leading to the emergence of radicals and initiate thereby the polymerization reaction of the monomer and oligomer, providing a transition of the composition from liquid to solid, with a spatial mesh stitched structure.

Thus, due to the intensive development of new technologies for the use of photo-cured polymers, it became necessary to create new special compositions based on materials with lower cost for 3D printers. In this regard, the purpose of this work is to develop and study the physical and mechanical properties of photo-cured compositions based on methacrylic acid esters.

in polyethylene glycol-400 dimethacrylate. Next, to the obtained solution was added olygoethyleneamines, dimethacrylates ether of triethylene glycol, tetraacrylate of pentaerythritol and permissively until smooth.

For the obtained compositions, the viscosity was studied using a rotational Brookfield viscometer. Compressive strength was tested according to GOST 4651-82 on a tensile testing machine REM-10-A-2.

is the composition obtained on the basis of polyethylene glycol dimethacrylate and triethylene glycol dimethacrylate ether at a ratio of 70:30.

Curing of the binder obtained was carried out under the action of UV light for 2-5 min.

Then the cured samples were kept for 14 days and their physical and mechanical properties were studied. 
From Table. 2 it can be seen that ylene glycol dimethacrylic ether at a ratio the composition based on polyethylene of 70:30 has the greatest strength. glycol dimethacrylate modified with trieth-

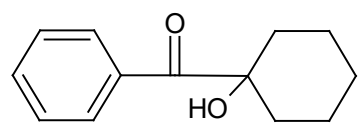<smiles>[C-]=Cc1cccc(C=[Te]C2CC2)c1</smiles><smiles>O=C(c1ccccc1)c1ccccc1</smiles><smiles>[R]CN([R])[3H]</smiles><smiles>[CH]C1CC1</smiles><smiles>[R]C[N+]([R])([R])OC(c1ccccc1)c1ccccc1</smiles><smiles>O[C](c1ccccc1)c1ccccc1</smiles><smiles>[R][CH]N([R])[R]</smiles>

Fig. 1. The mechanism of photoinitiation

The viscosity of the photocurable compositions Table 1 on the basis of olygoesteracrylates at room temperature

\begin{tabular}{c|l|c|c|c|c}
\hline \multirow{2}{*}{ № } & \multirow{2}{*}{ The name of the modifier } & \multicolumn{4}{|c}{ The content of the modifier, \% } \\
\cline { 3 - 6 } & & 0 & 10 & 20 & 30 \\
\cline { 3 - 6 } & & \multicolumn{4}{|c}{ Viscosity $\eta_{\mathrm{cp}}, \mathrm{mPa} \cdot \mathrm{s}$} \\
\hline 1 & Dimethacrylic triethylene glycol ether & 13262 & 15003 & 14755 & 13964 \\
\hline 2 & Oligourethandimethacrylate & 13262 & 34896 & 33268 & 35194 \\
\hline 3 & Tetraacrylate of pentaerythritol & 13262 & 12647 & 14945 & 21669 \\
\hline
\end{tabular}

Table 2

Physical and mechanical properties of photocurable formulations, based on olygoesteracrylates

\begin{tabular}{c|l|c|c|c|c}
\hline \multirow{2}{*}{ № } & \multirow{2}{*}{ The name of the modifier } & \multicolumn{4}{|c}{ The content of the modifier, \% } \\
\cline { 3 - 6 } & & 0 & 10 & 20 & 30 \\
\cline { 3 - 6 } & & 44.41 & 47.37 & 90.19 & 140.96 \\
\hline 1 & Dimethacrylic triethylene glycol ether & 44.41 & 48.96 & 54.62 & 73.94 \\
\hline 2 & Oligourethandimethacrylate & 44.41 & 56.19 & 71.75 & 81.98 \\
\hline 3 & Tetraacrylate of pentaerythritol & & & & \multicolumn{2}{|c}{ Uniform compressive strength $\delta, \mathrm{MPa}$} \\
\hline
\end{tabular}




\section{Conclusions}

Thus, in this work we have developed positions modified with triethylene glycol a photocurable coating based on the amal- dimethacrylic ether have the highest curing gam of polyethylene glycol and various rate and maximum strength.

cooligomers. It was found that the com-

\section{Acknowledgements}

The research was carried out under a grant for students from the Foundation for Support of Youth Startups of the FSBEI HE "Chuvash State University named after I. N. Ulyanov".

\section{References}

1. Deng L, Tang L, Qu J. Synthesis and photopolymerization of novel UV-curable macrophotoinitiators. Progress in Organic Coatings. 2020;141:105546. doi:10.1016/j.porgcoat.2020.105546

2. Quan $\mathrm{H}$, Zhang T, $\mathrm{Xu} \mathrm{H}$, Luo Sh, Nie J, Zhu X. Photo-curing $3 \mathrm{D}$ printing technique and its challenges. Bioactive Materials. 2020;5(1):110-5. doi:10.1016/j.bioactmat.2019.12.003

3. Babkin O.E. Polimernye pokrytiya UF-otverzhdeniya [Polymer coatings of UVcuring]. Saint-Petersburg: Spbgukit, 2012. 39 p. Russian. 